\title{
Efeitos da Taxa de Resfriamento na Soldagem do Aço API 5L-X80
}

\author{
Roberto Gomes Moojen"1, Ivan Guerra Machado로 , José Antônio Esmério Mazzaferro², Arnaldo Ruben Gonzalez² \\ 1 Laboratório de Soldagem \& Técnicas Conexas - LS\&TC, Programa de Pós-Graduação em Engenharia de Minas, Metalúrgica e \\ de Materiais - PPGE3M, Universidade Federal do Rio Grande do Sul - UFRGS, Porto Alegre, RS, Brasil. \\ 2 Laboratório de Soldagem \& Técnicas Conexas - LS\&TC, Programa de Pós-Graduação em Engenharia Mecânica - PROMEC, \\ Universidade Federal do Rio Grande do Sul - UFRGS, Porto Alegre, RS, Brasil.
}

Recebido: 15 Out., 2014

Aceito: 20 Mar., 2014

E-mails:

rgmoojen@gmail.com (RGM),welder@ ufgrs.br (IGM), mazza@ufrgs.br (JAEM), ruben@mecanica.ufrgs.br (ARG)
Resumo: Uma das principais razões para o desenvolvimento do aço API 5L-X80 foi seu uso em Regiões Polares, onde se faz necessário alta tenacidade em baixas temperaturas. Neste trabalho foi estudado o efeito da taxa de resfriamento na soldagem sobre as propriedades mecânicas e metalúrgicas deste tipo de aço. Estas diversas taxas de resfriamento simulam também diversas energias de soldagem. As diferentes taxas de resfriamento foram obtidas através de cinco distintos pré-aquecimentos. A temperatura de interpasse foi igual à temperatura de pré-aquecimento de cada uma das juntas em duplo $V$ com face de raiz, sendo as soldagens robotizadas realizadas por arco elétrico com gás de proteção e eletrodo consumível ("Metal Active Gas" - MAG), arame maciço com resistência mecânica equivalente ("matching") ao metal base e gás de proteção composto de $75 \%$ Ar e $25 \% \mathrm{CO}_{2}$. Para análise das juntas soldadas foram utilizados microscópio de luz e microscópio eletrônico de varredura (MEV), bem como ensaios mecânicos de tração, dobramento, impacto (Charpy-V) e dureza (Vickers). Os resultados dos testes mecânicos foram satisfatórios e apresentaram correlação com as análises metalúrgicas. As juntas apresentaram alta resistência ao impacto (Charpy-V) em temperaturas de teste de até $-40{ }^{\circ} \mathrm{C}$.

Palavras Chave: Soldagem; API 5L-X80; Taxas de resfriamento; Propriedades mecânicas.

\section{Cooling Rate Effects in the Welding of API 5L-X80 Steel}

\begin{abstract}
One of the main reasons for the development of the API 5L-X80 steel was its utilization in Polar Areas where a relatively high toughness in low temperatures is needed. The present work aimed at studying the welding cooling rate effects on the mechanical and metallurgical properties of this type of steel. These various cooling rates also simulate various heat input's. These different cooling rates were obtained through five distinct pre-heatings. The interpass temperature was the same of the pre-heating temperature presented by each one of the double $V$ joints with root face; being the robotics weldings itself performed through gas metal arc welding (GMAW), using solid wire with matching mechanical resistance, and as a shielding gas a mixture of $75 \% \mathrm{Ar}$ and $25 \% \mathrm{CO}_{2}$. In order to analyze the welded joints, light microscope and scanning electron microscope (SEM) were utilized, as well as mechanical tests, such as tension, bending, impact (Charpy-V) and hardness (Vickers). The results of such mechanical tests were satisfactory and suitable correlated with the metallurgical analyses. The joint presented a high Charpy- $V$ impact resistance in testing temperatures up to $-40^{\circ} \mathrm{C}$.
\end{abstract}

Key-words: Welding; API 5L-X80 steel; Cooling rates; Mechanical properties.

\section{Introdução}

Com o crescente consumo de óleo e gás e com as novas reservas sendo descobertas em ambientes hostis e afastados dos grandes centros de consumo, o uso de aços API de graus mais elevados torna-se ainda mais necessário, sendo o aço API 5L-X80 adequado para este propósito por sua combinação de alta resistência mecânica e tenacidade. Devido a união por soldagem ser um dos processos mais importantes na construção de uma dutovia, é fundamental conhecer quais microestruturas e propriedades mecânicas serão obtidas em determinadas condições.

O uso de processo de soldagem robotizado realizado por arco elétrico com gás de proteção e eletrodo consumível ("Metal Active Gas" - MAG) permite realizar soldas de boa qualidade, e com uma taxa de deposição superior ao processo MAG soldado manualmente.
Este é um artigo publicado em acesso aberto (Open Access) sob a licença Creative Commons Attribution Non-Commerc que permite uso, distribuição e reproduçăo em qual q'uer meio, sem restriçōes desde que sem fins comerciais e que 0 trabalho original seja corretamente citado. 
Neste trabalho foram analisadas as transformações mecânicas e metalúrgicas que ocorreram nas juntas soldadas e os resultados correlacionados com a taxa de resfriamento. As diferenças nas taxas de resfriamento, bem como o tempo de permanência em altas temperaturas, causaram mudanças microestruturais significativas. As análises dos ciclos térmicos não se restringiram somente à taxa de resfriamento, mas também ao tempo em que a junta permaneceu sob altas temperaturas.

As diferentes taxas de resfriamento obtidas neste trabalho podem ser correlacionadas com diversas energias de soldagem, auxiliando em futuros projetos de soldagem do aço API $5 \mathrm{~L}-\mathrm{X} 80$. Como a velocidade de avanço de uma dutovia depende da velocidade de execução do passe de raiz, e o número de passes de enchimento determina o número de estações de soldagem. Quanto maior for a taxa de deposição (baixa taxa de resfriamento) mais rapidamente e com menor custo a dutovia será construída, dado ser necessário um menor número de passes de soldagem. Uma não incidência de defeitos também é desejável.

Foram empregadas cinco diferentes temperaturas de pré-aquecimento, sendo elas: -30, 40, 100, 150 e $200{ }^{\circ} \mathrm{C}$. Será tomada a liberdade neste artigo de se chamar $-30^{\circ} \mathrm{C}$ como sendo pré-aquecimento, embora tenha sido realizado um resfriamento antes de cada passe de solda. As temperaturas de interpasse foram iguais às do pré-aquecimento a fim de serem obtidas distintas taxas de resfriamento.

As duas menores temperaturas estudadas podem causar trincas nas juntas devido a suas altas taxas de resfriamento. A temperatura mínima recomendada de pré-aquecimento para soldar o API $5 \mathrm{~L}-\mathrm{X} 80$ com baixo risco de causar defeitos é de $100^{\circ} \mathrm{C}$ [1]. Porém, pode-se afirmar que pela alta tenacidade do X80 e com o uso de consumíveis de baixo hidrogênio, é possível realizar a solda com menores temperaturas de pré-aquecimento e de interpasse, sem risco de trincas [1]. Além disto, processos de soldagem usando robôs permitem realizar cordões de soldas com menores áreas de ZAC (Zona Afetada pelo Calor) e é possível obter microestrutura refinada (ou bainíticas) quando comparado ao processo manual de soldagem por eletrodo revestido [2].

\section{Materiais e Métodos}

Foram soldadas seções de 340 mm de arco e 340 mm de largura, extraídas de um duto API 5L-X80 com 32 mm de espessura e diâmetro de $810 \mathrm{~mm}$, formando um total de cinco conjuntos de juntas a topo com chanfro duplo V com face de raiz; as dimensões do chanfro são mostradas na Figura 1. As temperaturas de interpasse para cada junta soldada foram iguais às temperaturas de pré-aquecimento para simular distintas condições de soldagem e, consequentemente, diferentes taxas de resfriamento. A soldagem somente era realizada quando a temperatura do segmento de duto atingia a temperatura de pré-aquecimento. Foi utilizado o processo de soldagem ao arco elétrico com gás de proteção e eletrodo consumível (“Metal Active Gas" - MAG).

Na Tabela 1 está a composição química do API 5L-X80, um tipo de aço microligado pertencente à classe $\mathrm{Nb} / \mathrm{Cr} / \mathrm{Mo}$. O Pcm (Parâmetro de Ito e Besho) é um método para cálculo do carbono equivalente desenvolvido para aços de baixa liga, utilizado também pela norma API 1104 [3]. Este método é o mais indicado para o cálculo do carbono equivalente para aços com menos de 0,12\% de carbono. O Pcm calculado para o API 5L-X80 foi de 0,18\%, abaixo dos 0,25\% que a norma API 5L [4] estipula como máximo.

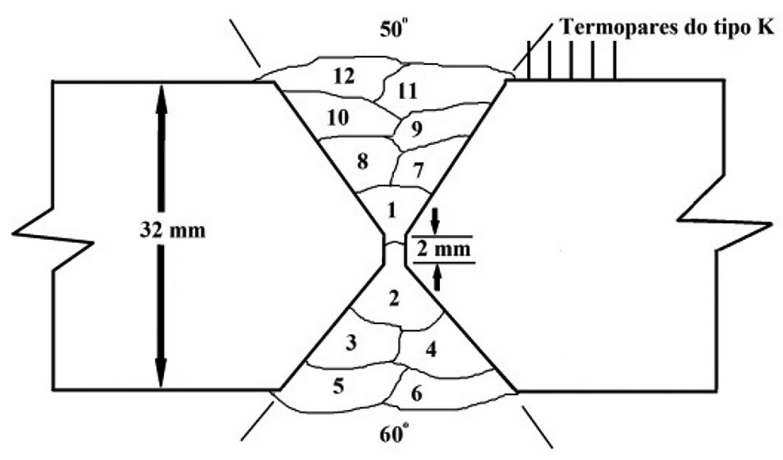

Figura 1. Representação esquemática dos passes de soldagem, e das posições dos termopares. 
A soldagem MAG foi robotizada, com gás de proteção $75 \%$ Ar e $25 \% \mathrm{CO}_{2}$, juntamente com o arame AWS ER $80 \mathrm{~S}-\mathrm{G}$ com 1,2 mm de diâmetro. A vazão do gás de proteção foi de $15 \mathrm{l} / \mathrm{min}$ com distância do bico de contato até a peça de $20 \mathrm{~mm}$. Para preencher o chanfro foram realizados 12 passes de solda na posição de soldagem plana, conforme mostrado na Figura 1, sendo realizado um passe de raiz, um passe de raiz inferior e dez passes de enchimento. Após a soldagem do passe de raiz (passe número um), a junta foi girada possibilitando a execução do passe de raiz inferior (passe número dois), e mais quatro passes de enchimento (passes três a seis). Finalmente, a junta foi novamente virada e mais seis passes de enchimento foram realizados (passes sete a doze). Esta sequência de passes reduziu a deformação da junta soldada.

Na Tabela 2 são mostrados os parâmetros de soldagem usados nos diversos passes realizados para preencher o chanfro. O passe de raiz não foi realizado com um valor maior de corrente de soldagem para evitar que o chanfro furasse nas maiores temperaturas de pré-aquecimento. $O$ passe de raiz inferior serviu para garantir uma penetração completa na face de raiz da junta. A combinação desses parâmetros serviu para realizar soldagens com energias entre $1,1 \mathrm{~kJ} / \mathrm{mm}$ e $1,3 \mathrm{~kJ} / \mathrm{mm}$, nos passes de enchimento, cujo objetivo era evitar na raiz crescimento excessivo dos grãos e desta forma obter elevada energia absorvida no ensaio de impacto [5,6]. Os passes de raiz e raiz inferior foram executados com uma energia de $1,1 \mathrm{~kJ} / \mathrm{mm}$ e $1,8 \mathrm{~kJ} / \mathrm{mm}$ respectivamente.

A verificação da temperatura foi feita em pontos específicos utilizando termopares do tipo $\mathrm{S}$ e do tipo K. Os termopares do tipo $S$ tinham um diâmetro de $0,3 \mathrm{~mm}$ e os Termopares do tipo $\mathrm{K}$ tinham um diâmetro de $0,9 \mathrm{~mm}$. Termopares do tipo $S$ foram "arpoados" (inseridos) na poça de fusão, nas posições de $1 / 3$ e na metade do comprimento do cordão de solda em todos os passes de soldagem. Os termopares do tipo $\mathrm{K}$ foram soldados na metade do comprimento do cordão, mediante descarga elétrica de capacitores, nas distâncias de 2, 4, 6, 8 e $10 \mathrm{~mm}$ da borda do chanfro, (conforme pode ser visto na Figura 1). Na mesma posição em que estavam os termopares do tipo $\mathrm{K}$ e o termopar do tipo $\mathrm{S}$, foi cortada uma seção transversal ao eixo da solda, objetivando obtenção de macrofotografias e, também, microfotografias com o uso de microscopia de luz.

Três corpos de prova para ensaio de tração e dez corpos de prova para Charpy-V foram cortados de cada junta soldada. Os corpos de prova de tração de seção reduzida foram ensaiados em temperatura ambiente, com seção transversal de $6 \times 6 \mathrm{~mm}$ e comprimento útil de $50 \mathrm{~mm}$, segundo a norma NBR 6152 [7]. Os corpos de prova Charpy-V foram testados em três temperaturas de ensaio, sendo elas: 20,0 e $-40^{\circ} \mathrm{C}$. Pelo menos três amostras foram ensaiadas em cada temperatura de ensaio. Uma amostra para o ensaio de dobramento foi cortada do centro da junta soldada para análise dos passes de raiz e de enchimento, sendo utilizado punção com $19 \mathrm{~mm}$ de diâmetro, segundo a norma ASTM E190 [8]. As amostras para o ensaio de dobramento foram lixadas até a lixa \#600 e atacadas com Nital $10 \%$ para revelar a solda e garantir seu preciso posicionamento no centro do penetrador.

Imagens de MEV foram obtidas das superfícies de fratura dos corpos de prova Charpy-V e dos corpos de prova de tração, para análise dos micro mecanismos de fratura. As microestruturas do metal base, das três regiões da ZAC e do metal de solda, foram analisadas por meio de microscopia de luz. A mesma amostra utilizada para

Tabela 1. Composição química do aço API $5 \mathrm{~L}-\mathrm{X} 80$ (\% em massa).

\begin{tabular}{cccccccccc}
\hline Elemento & $\mathbf{C}$ & $\mathbf{S i}$ & $\mathbf{M n}$ & $\mathbf{P}$ & $\mathbf{S}$ & $\mathbf{C r}$ & $\mathbf{M o}$ & $\mathbf{N i}$ & $\mathbf{A l}$ \\
& $\mathbf{0 , 0 6}$ & $\mathbf{0 , 2}$ & 1,9 & $<0,001$ & $<0,001$ & 0,11 & 0,14 & 0,24 & 0,0236 \\
\hline Elemento & $\mathbf{N b}$ & $\mathbf{T i}$ & $\mathbf{V}$ & $\mathbf{W}$ & $\mathbf{P b}$ & $\mathbf{S n}$ & $\mathbf{B}$ & $\mathbf{C u}$ & $\mathbf{F e}$ \\
& 0,04 & 0,01 & $<0,001$ & $<0,01$ & $<0,002$ & $<0,001$ & $<0,0001$ & 0,0201 & Bal. \\
\hline
\end{tabular}

Tabela 2. Parâmetros da Soldagem MAG.

\begin{tabular}{lccccc}
\hline Passe (s) & Corrente (A) & Tensão $(\mathbf{V})$ & $\begin{array}{c}\text { Velocidade de } \\
\text { soldagem }(\mathbf{m m} / \mathbf{s})\end{array}$ & $\begin{array}{c}\text { Ângulo de } \\
\text { soldagem ( }\left(^{\circ}\right)\end{array}$ & $\begin{array}{c}\text { Ângulo de } \\
\text { deslocamento }\left(^{\circ}\right)\end{array}$ \\
Raiz & 270 & 30 & 7 & 0 & 0 \\
Enchimento & 300 & 32 & 7 & 15 & $\pm 10^{*}$ \\
Raiz inferior & 370 & 35 & 7 & 0 & 0 \\
\hline
\end{tabular}

* Nota: O Ângulo de Deslocamento foi de $10^{\circ}$ atacando preferencialmente o metal base, sendo que a cada passe ele foi alterado para garantir uma melhor qualidade da junta. 
medir a geometria foi lixada até a lixa \#1.200 mesh e polida, logo atacada com Nital 4\% por dois segundos antes de ser analisada no microscópio de luz. Após a análise no microscópio de luz a amostra foi novamente polida e atacada duas vezes com Nital $4 \%$ por quatro segundos para análise no MEV.

Cinco perfis de dureza Vickers com carga de $5 \mathrm{~kg}$ e com espaçamento de $1 \mathrm{~mm}$ entre cada indentação foram realizados sobre cada amostra. A dureza do metal base foi medida e o seu valor ficou próximo de 225 HV5, não tendo sido alterado pelos ciclos térmicos. O primeiro perfil foi realizado a $2 \mathrm{~mm}$ da superfície externa do duto; o segundo foi realizado a $9 \mathrm{~mm}$ da superfície externa; o terceiro foi realizado a $18 \mathrm{~mm}$ da superfície externa; o quarto foi realizado a $22 \mathrm{~mm}$ da superfície externa e o quinto foi realizado a $30 \mathrm{~mm}$ da superfície externa.

\section{Resultados e Discussões}

A Figura 2 mostra as macrofotografias das juntas soldadas com pré-aquecimentos e temperaturas de interpasse extremas (i. e., $-30^{\circ} \mathrm{C}$ e $200^{\circ} \mathrm{C}$ ). A análise destas macrofotografias e das demais mostram que elas não possuem nenhum defeito visível ao olho nu tais como falta de fusão, porosidade ou sobreposição. Esta mesma figura apresenta também as cinco trajetórias sobre as quais foi medida dureza de cada junta soldada, servindo para melhorar a compreensão dos perfis de dureza que serão mostrados a seguir.

\subsection{Macrofotografias}

A menor área da ZAC foi medida na soldagem realizada a $-30^{\circ} \mathrm{C}$, e a área da ZAC aumentou com o acréscimo da temperatura de pré-aquecimento.

A ZAC da junta soldada realizada com pré-aquecimento e temperatura de interpasse de $200^{\circ} \mathrm{C}$ foi $64 \%$ maior do que a realizada com $-30^{\circ} \mathrm{C}$. A diluição das soldas ficou em torno de $25 \%$ para todos os casos, sem variação significativa com o aumento do pré-aquecimento.

\subsection{Dureza Vickers}

As maiores durezas foram medidas no metal de solda, para todas as juntas soldadas; entretanto, a maior dureza foi medida no metal de solda produzido a $-30^{\circ} \mathrm{C}$, seguida pela solda realizada com pré-aquecimento e temperatura de interpasse de $40^{\circ} \mathrm{C}$, tendo as demais soldas valores similares de dureza. As medições de dureza iniciaram no metal base afastado da região da solda, percorrendo a ZAC, o metal de solda, a ZAC e só terminaram no metal base afastado da ZAC. As maiores durezas foram medidas no centro do metal de solda, reduzindo-se na ZAC até chegar ao valor de dureza do metal base para depois manter-se constante nesse mesmo metal. $\mathrm{O}$ comportamento da dureza aconteceu de acordo com o previsto, ou seja, a junta soldada com a maior taxa de resfriamento apresentou maior dureza e com a redução da taxa de resfriamento as durezas medidas foram inferiores.

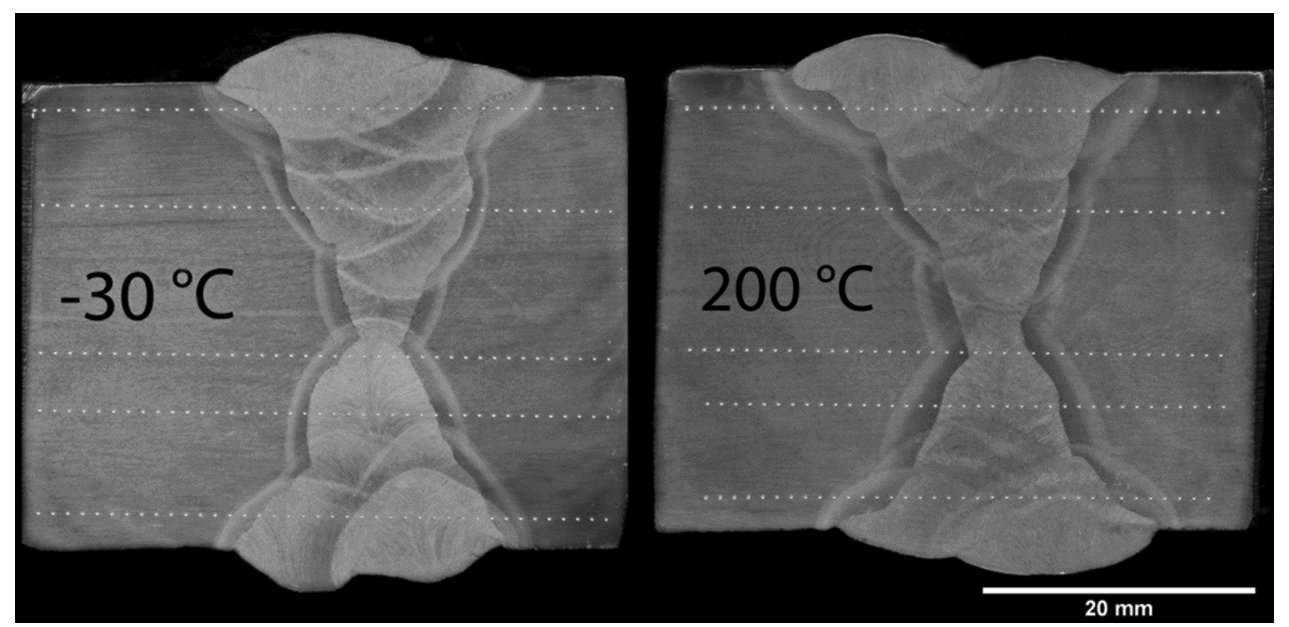

Figura 2. Macrofotografia das juntas soldadas com as indentações resultantes do ensaio de dureza Vickers. As temperaturas de pré-aquecimento e de temperatura de interpasse estão indicadas sobre as respectivas amostras. 
As Figuras 3 e 4 mostram os perfis de dureza medidas nas juntas soldadas nas diversas distâncias da superfície externa do duto e para os pré-aquecimentos de -30 e $200^{\circ} \mathrm{C}$, respectivamente. Infelizmente não é possível mostrar nos perfis de dureza a qual região da junta soldada cada ponto pertence.

$\mathrm{Na}$ soldagem realizada com $40^{\circ} \mathrm{C}$ de pré-aquecimento, os perfis de dureza que apresentaram os maiores valores foram medidos no centro da junta e na metade do chanfro inferior. $\mathrm{O}$ aço API $5 \mathrm{~L}-\mathrm{X} 80$ por ser um aço microligado, pode sofrer Baking em temperaturas superiores a $100^{\circ} \mathrm{C}$. A junta soldada com $-30{ }^{\circ} \mathrm{C}$ de pré-aquecimento, foi resfriada com nitrogênio líquido e as maiores durezas foram medidas próximas às superfícies internas e externas do duto, devido às maiores taxas de resfriamento nessas duas superfícies. Nos demais pré-aquecimentos, os maiores valores de durezas foram medidos na metade do chanfro superior e próximos da superfície interna do duto.

As maiores durezas que foram medidas na ZAC e no metal base próximo à ZAC e podem ser atribuídas ao processo de têmpera e revenido pelos passes subsequentes. Este endurecimento somente ocorre em aços onde uma pequena fração de martensita é formada e quando possuem elementos que promovem endurecimento secundário $[6,9,10]$.

A soldagem realizada com $40^{\circ} \mathrm{C}$ foi a que permaneceu por mais tempo em altas temperaturas devido ao seu lento resfriamento. A temperatura do ar nos dias em que os experimentos foram realizados estava em torno de $30^{\circ} \mathrm{C}$. O resfriamento foi realizado ao ar com circulação artificial, com a temperatura de interpasse igual à temperatura de pré-aquecimento para todas as juntas soldadas. Quanto maior a temperatura de pré-aquecimento,

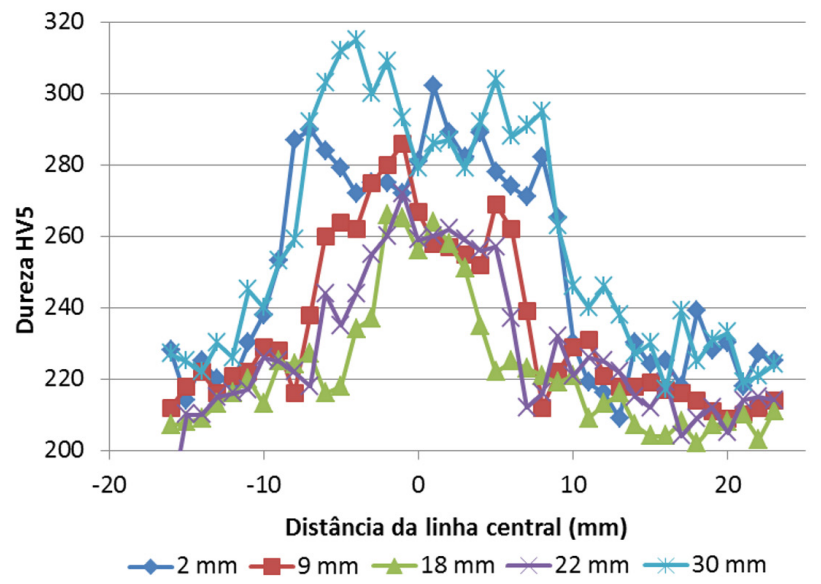

Figura 3. Perfis de dureza da junta soldada com pré-aquecimento e temperatura de interpasse de $-30{ }^{\circ} \mathrm{C}$.

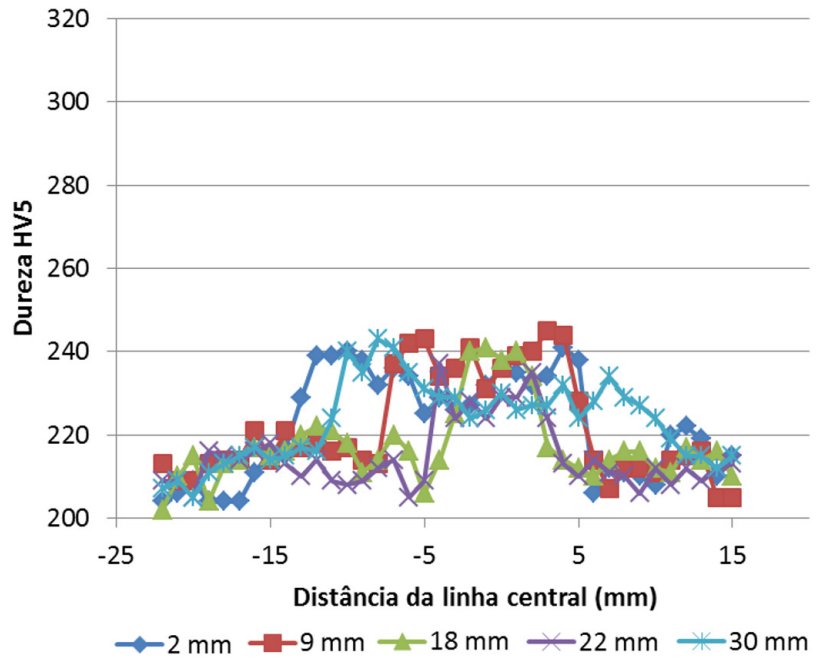

Figura 4. Perfis de dureza da junta soldada com pré-aquecimento e temperatura de interpasse de $200^{\circ} \mathrm{C}$. 
menor o intervalo de tempo para atingir a temperatura de interpasse. No caso da soldagem a $40{ }^{\circ} \mathrm{C}$, mais de duas horas de resfriamento ao ar foram necessárias após cada passe de soldagem; enquanto que nos demais pré-aquecimentos este tempo não passou de 20 minutos. O maior tempo que a junta soldada a $40^{\circ} \mathrm{C}$ permaneceu em altas temperaturas provavelmente resultou no envelhecimento do metal base, produzindo valores mais elevados de resistência mecânica, tensão de escoamento e menor ductilidade.

Estudo [11] da ZAC de um API 5L-X80 soldado por friç̧ão determinou que quanto maiores os tamanhos dos blocos de bainita, mais dura serão as microestruturas. Observe-se que na soldagem realizada com $40{ }^{\circ} \mathrm{C}$ de pré-aquecimento foram encontrados grandes blocos de bainita e do microconstituinte martensita-austenita (MA). Sendo os blocos de MA encontrados nesta solda os maiores dentre todos os pré-aquecimentos utilizados.

\subsection{Termopares e energia de soldagem}

O tempo em que a junta soldada permanece no intervalo de temperaturas entre $800{ }^{\circ} \mathrm{C}$ e $500{ }^{\circ} \mathrm{C}\left(\Delta \mathrm{t}_{8 / 5}\right)$ durante o resfriamento de cada passe de solda foi medido através de termopares do tipo $S$ "arpoados" na poça de fusão, cujos resultados estão na Figura 5. $O \Delta \mathrm{t}_{8 / 5}$ é um importante dado acerca da taxa de resfriamento do metal de solda, sendo muito utilizado na comparação de taxas de resfriamento. É importante mencionar, que existem diversos fatores que afetam este $\Delta \mathrm{t}_{8 / 5}$, entre eles: o modo de extração do calor se altera de bidimensional no passe de raiz para tridimensional nos passes de cobertura; as diferentes energias de soldagem; os distintos pré-aquecimentos. Aqui serão considerados os efeitos dos dois últimos fatores, pois as geometrias dos cordões de solda são similares nas juntas produzidas.

Para cada uma das temperaturas de pré-aquecimento do metal base, o passe de raiz apresentou o menor $\Delta \mathrm{t}_{8 / 5^{\prime}}$ isto é consequência da menor energia de soldagem $(1,1 \mathrm{~kJ} / \mathrm{mm})$ aplicada e o passe de raiz inferior apresentou os maiores valores do $\Delta \mathrm{t}_{8 / 5}$, pois foi soldado com a maior energia de soldagem $(1,8 \mathrm{~kJ} / \mathrm{mm})$. Nos passes de enchimento das soldas realizadas com 40 e $100^{\circ} \mathrm{C}$ é significativo o aumento do $\Delta \mathrm{t}_{8 / 5}$. Isso ocorreu devido à medida da temperatura ter sido executada nas superfícies externa e interna do duto e o resfriamento ter ocorrido ao ar livre, não sendo lento o suficiente para garantir homogeneidade de temperaturas na peça. Esta falta de homogeneidade levou à região a ser soldada a permanecer em temperaturas superiores àquelas de pré-aquecimento e esta temperatura foi se tornando maior após cada passe de soldagem, resultando em redução da taxa de resfriamento.

No sétimo passe de cada junta soldada, exceto para a soldagem realizada com $40^{\circ} \mathrm{C}$ é marcante a redução no $\Delta t_{8 / 5}$, sendo esse o primeiro passe de enchimento da porção superior da junta (lado externo do duto). Neste caso, a junta recém tinha sido girada e reaquecida. $O$ processo de girar a seção de duto e a reprogramação do robô de soldagem demorava mais do que o tempo necessário para o seu resfriamento até a temperatura de

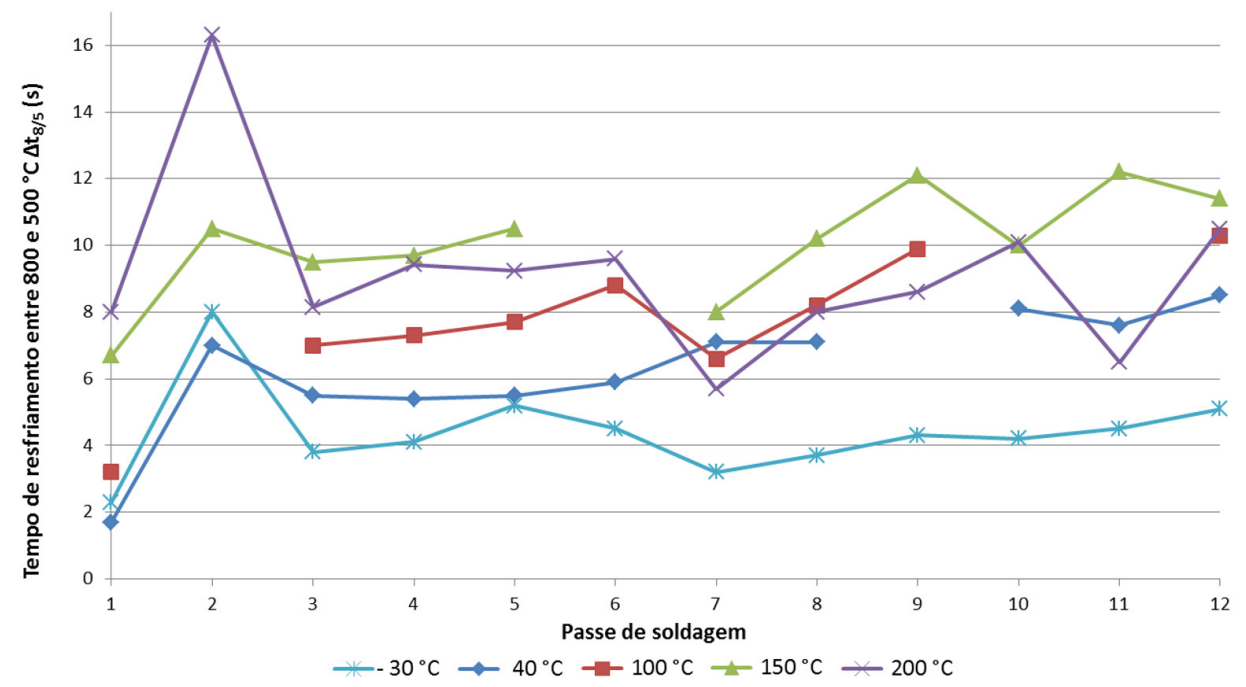

Figura 5. Tempo de resfriamento $\left(\Delta \mathrm{t}_{8 / 5}\right)$ em função da temperatura de pré-aquecimento e do passe de solda. Observe-se que para alguns passes a medição da temperatura não foi realizada. 
pré-aquecimento, sendo imprescindível reaquece-la. Este reaquecimento levou a temperatura da região a ser soldada estar inferior a de pré-aquecimento. No caso da soldagem realizada com $-30^{\circ} \mathrm{C}$ de pré-aquecimento, a junta foi resfriada com nitrogênio líquido assim como nos demais passes, mas como não havia acúmulo de energia térmica dos passes anteriores na região a ser soldada, $\mathrm{o} \Delta \mathrm{t}_{8 / 5}$ deste passe também foi menor. Na junta soldada com pré-aquecimento e temperatura de interpasse de $40{ }^{\circ} \mathrm{C}$ foi evidente um aumento no $\Delta t_{8 / 5}$ de um passe de soldagem para outro. Este aumento no $\Delta \mathrm{t}_{8 / 5}$ foi devido à temperatura no interior da junta não ter chegado à de pré-aquecimento após cada passe de soldagem, mesmo com duas horas de resfriamento e a temperatura das superfícies do duto já tivesse atingido a temperatura de pré-aquecimento.

Nos demais pré-aquecimentos estudados ocorreu um pequeno aumento no $\Delta \mathrm{t}_{8 / 5}$ de um passe para outro, embora esse aumento tenha sido menos evidente.

Termopar do tipo $S$ foi utilizado na obtenção das curvas de temperatura em função do tempo, para determinar o ciclo térmico (taxas de resfriamento), assim como o tempo de permanência nas temperaturas entre 800 e $500^{\circ} \mathrm{C}$, conforme exemplificado para os pré-aquecimentos de $-30^{\circ} \mathrm{C}$ e $200^{\circ} \mathrm{C}$ nas Figuras 6 e 7. Essa mudança na taxa de resfriamento é devida à nucleação da ferrita acicular no metal de solda. Estudo [12] mostrou os efeitos de várias taxas de resfriamento no metal de solda, sendo construído diagrama CCT do metal de solda para aços baixa liga. Para obter à taxa de resfriamento foi utilizada a técnica de arpoar um termopar do tipo $S$ na poça de fusão, constituindo a mesma técnica utilizada na presente investigação. É afirmado neste trabalho que esta mudança na taxa de resfriamento é devido à nucleação da ferrita acicular, por ser esta a microestrutura mais vista nas microfotografias. Outros autores também afirmaram que a nucleação da ferrita acicular causa uma mudança na taxa de resfriamento muito semelhante às encontradas neste trabalho.

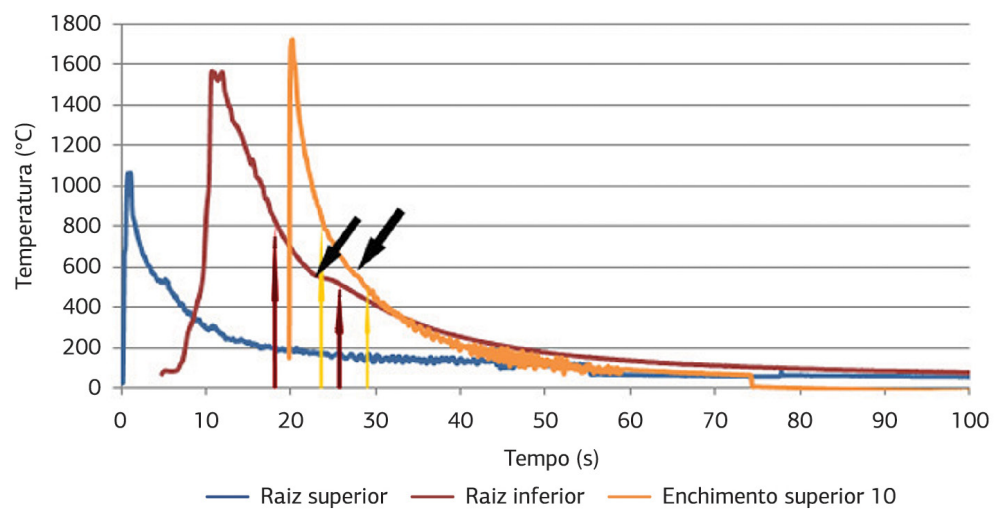

Figura 6. Ciclo térmico do metal de solda depositado com pré-aquecimento e temperatura de interpasse de $-30^{\circ} \mathrm{C}$. As setas mais espessas indicam a temperatura de transformação e as verticais as temperaturas de 800 e $500^{\circ} \mathrm{C}$.

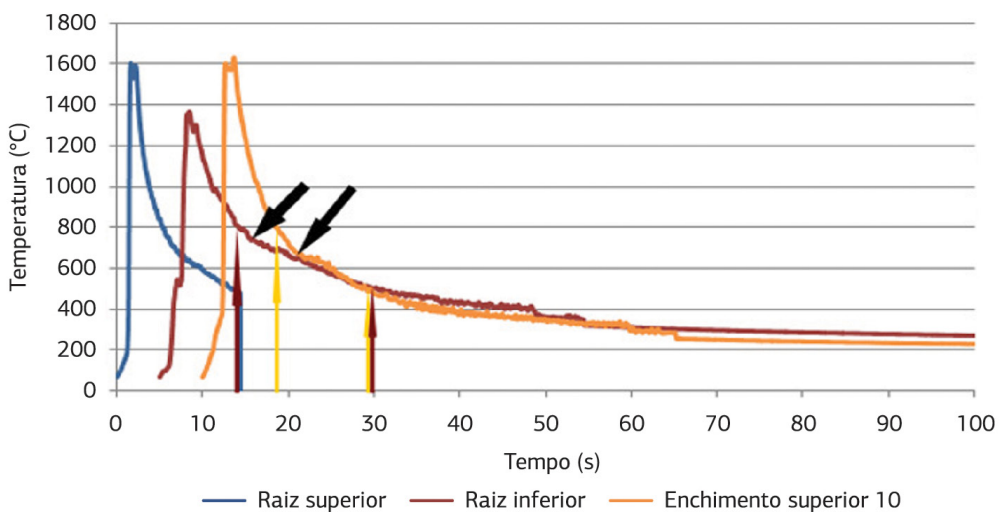

Figura 7. Ciclo térmico do metal de solda depositado com pré-aquecimento e temperatura de interpasse de $200^{\circ} \mathrm{C}$. As setas mais espessas indicam a temperatura de transformação e as verticais as temperaturas de 800 e $500^{\circ} \mathrm{C}$. 
Outros estudos [13,14] aplicaram diversas taxas de resfriamento a aços de alta resistência mecânica e baixa liga e determinaram que a temperatura de início da formação da ferrita acicular dependia da taxa de resfriamento. Igualmente foi determinado [13] que altas taxas de resfriamento levaram a menores temperaturas de início da transformação da austenita para ferrita. Quanto menor a temperatura de início da transformação da austenita para ferrita, mais refinada e dura será a nova fase. As temperaturas determinadas por este último estudo para o início da transformação (entre 550 e $600^{\circ} \mathrm{C}$ ) foram próximas daquelas medidas no presente trabalho.

As medidas da temperatura do início da transformação foram realizadas através dos ciclos térmicos e de sua derivada segunda em relação ao tempo. Esta derivada foi executada no Excel utilizando os dados de tempo e temperatura adquiridos durante a soldagem. O gráfico da derivada segunda em função do tempo foi plotado e foi medido o instante em que ocorreu a inflexão, voltando ao gráfico de tempo e temperatura foi possível determinar a temperatura de início da transformação. As medições das temperaturas do final da reação não foram possíveis de serem executadas, pois não era possível medi-las com precisão. Isto se deve à existência de ruído no sinal do termopar de algumas amostras e pelo fato da temperatura estar próxima à temperatura de interpasse.

Nas Figuras 6 e 7 as flechas indicam a temperatura de início da formação da ferrita acicular no metal de solda. A seta da esquerda mostra o início da nucleação da ferrita acicular no passe de raiz inferior, e a seta da direita mostra a temperatura de início da nucleação da ferrita acicular no último passe de enchimento.

Na Tabela 3 é mostrada a relação entre a temperatura de início da transformação da ferrita acicular em função da temperatura de interpasse, sendo que, em geral, com o aumento na temperatura de interpasse, esta temperatura tendeu a aumentar. Muitos fatores interferem na temperatura de início da transformação, o que acaba por gerar um alto desvio padrão nos resultados. Dentro destes erros o maior foi a incerteza da temperatura de interpasse, como já foi visto a medida da temperatura nas superfícies do duto se mostrou um método impreciso levando a um aumento do erro da medição.

A temperatura de início da transformação foi medida nos passes de enchimento das juntas, pois todos os passes de enchimento foram dados com a mesma energia de soldagem. Não aparece nesta Tabela os resultados dos passes de raiz e raiz inferior. Porém, com pré-aquecimento de $200^{\circ} \mathrm{C}$ ocorreu redução na temperatura de início da transformação, em relação ao pré-aquecimento de $150^{\circ} \mathrm{C}$. Este decréscimo pode estar relacionado com o menor $\Delta \mathrm{t}_{8 / 5}$ desta junta soldada. Ressalto que esta variação foi muito pequena para afirmar que a taxa de resfriamento afetou a temperatura de início da transformação.

\subsection{Ensaios de tração}

Na Figura 8 são mostrados os valores da tensão de escoamento e da resistência à tração das amostras em função da temperatura de pré-aquecimento e da temperatura de interpasse. Em todos os casos a tensão de escoamento foi superior ao mínimo requerido pela norma API 1104 [3]. A tensão de escoamento aumentou juntamente com o acréscimo no pré-aquecimento de -30 para $40{ }^{\circ} \mathrm{C}$ e depois sofreu redução com o aumento da temperatura de pré-aquecimento. A amostra soldada com $40{ }^{\circ} \mathrm{C}$ de pré-aquecimento obteve a maior tensão de escoamento de todas as juntas soldadas neste trabalho, devido a esta amostra ter permanecido por mais tempo em altas temperaturas, o tempo de soldagem desta junta foi de 14 horas, nas demais juntas o tempo foi inferior a 5 horas, o que provavelmente causou um envelhecimento. Infere-se que o efeito da temperatura e do tempo tenham afetado o comportamento no ensaio de tração da junta soldada, obtendo-se a maior tensão de escoamento. A amostra soldada com $-30^{\circ} \mathrm{C}$ de pré-aquecimento e temperatura de interpasse foi resfriada após cada passe de soldagem, tendo sido soldada no menor intervalo de tempo.

Tabela 3. Temperatura de início da transformação da ferrita acicular em função da temperatura de pré-aquecimento.

\begin{tabular}{cc}
\hline Temperatura de pré-aquecimento ${ }^{\circ} \mathbf{C}$ & Temperatura início da transformação ${ }^{\circ} \mathbf{C}$ \\
-30 & $600 \pm 19$ \\
40 & $650 \pm 18$ \\
100 & $660 \pm 22$ \\
150 & $680 \pm 24$ \\
200 & $660 \pm 20$ \\
\hline
\end{tabular}


Todas as amostras tiveram a relação entre a tensão de escoamento e tensão de ruptura inferior à relação máxima de 0,93 estipulada pela norma API 5L [4]. Todas as fraturas do ensaio de tração ocorreram no metal base inalterado, conforme Figura 9, isso demonstra que a soldagem melhorou a resistência mecânica da junta. Na Figura está indicada a temperatura de pré-aquecimento e de interpasse e logo após a ordem em que foi ensaiada, as amostras foram atacadas com Nital $10 \%$ após o ensaio para revelar o metal de solda e a ZAC.

Estudo [15] de tratamentos térmicos no aço API 5L-X80 determinou que os ciclos térmicos podem provocar aumento da resistência mecânica do aço, tanto no limite de escoamento como no limite de ruptura, sem afetar a sua dureza. Nas amostras usinadas para o ensaio de tração, o comprimento útil utilizado foi de $50 \mathrm{~mm}$, com a solda localizada na porção central. Ao lado da solda estava a ZAC e a seguir o metal base que sofreu ciclos de aquecimento e resfriamento durante os sucessivos passes de soldagem. Estes aquecimentos e resfriamentos são comparáveis ao tratamento térmico de baking, que aumenta a resistência mecânica do aço. Como as amostras não possuíam um grande comprimento de seção útil, provavelmente todo o comprimento de metal base havia sofrido baking e, portanto, a tensão de escoamento e o limite de ruptura da junta soldada foram superiores às do metal base.

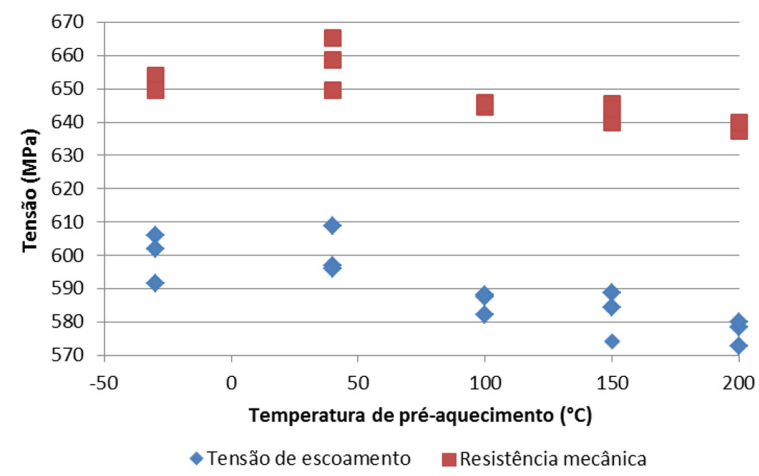

Figura 8. Tensão de escoamento e resistência à tração das juntas soldadas em função da temperatura de pré-aquecimento.
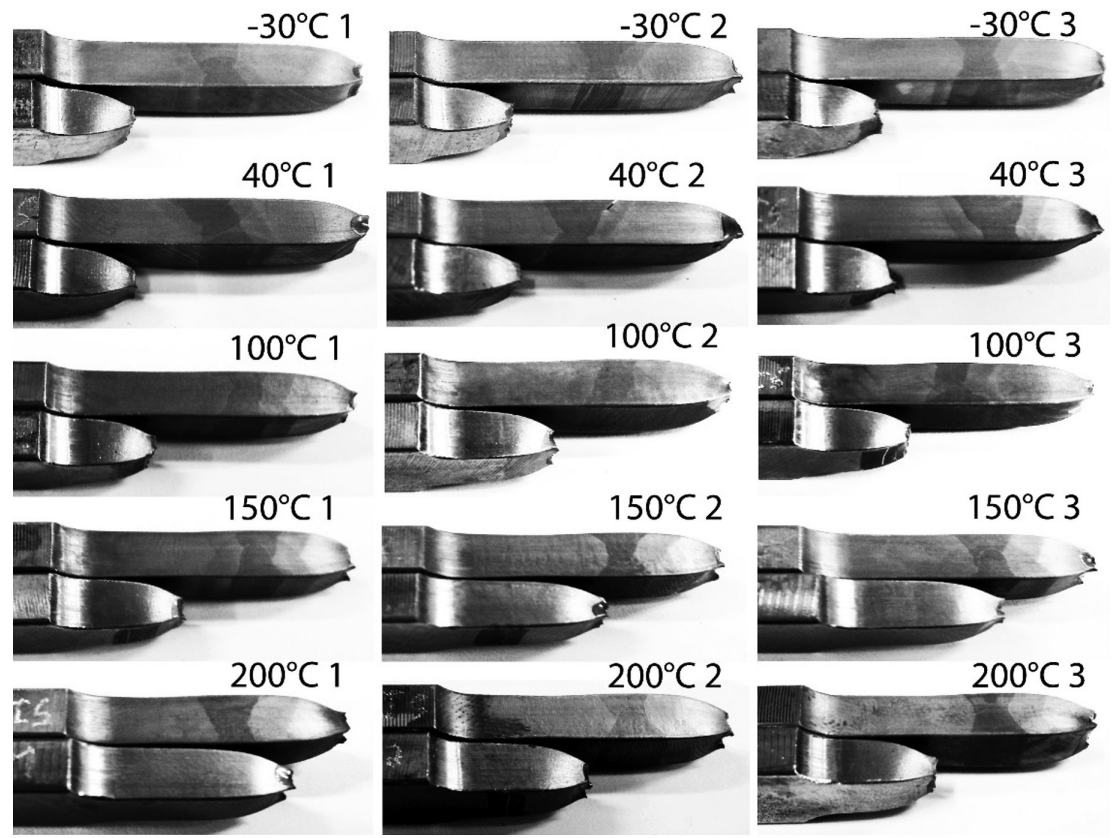

$150^{\circ} \mathrm{C} 2$
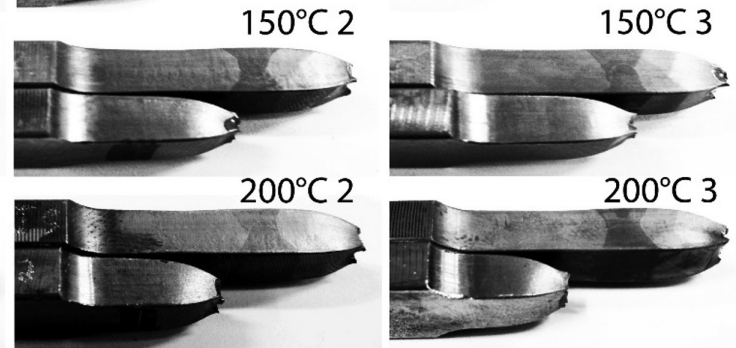

Figura 9. Corpos de prova de tração após o ensaio, mostrando que a fratura ocorrera no metal base. 
A Figura 10 mostra as imagens obtidas no MEV das superfícies de fratura das amostras no ensaio de tração. As fraturas ocorreram de modo dúctil como pode ser verificado pelas microcavidades nas amostras.

\subsection{Ensaio Charpy-V}

A Figura 11 mostra a energia absorvida no ensaio de impacto Charpy-V do metal de solda, em função da temperatura de realização do teste, do pré-aquecimento e da temperatura de interpasse utilizada. Nessa figura os resultados do metal base foram colocados na temperatura de pré-aquecimento de $0{ }^{\circ} \mathrm{C}$ para permitir comparação com os resultados das juntas. Cada junta soldada e o metal base foram testados pelo menos três vezes em cada temperatura de impacto, sendo as temperaturas de impacto 20,0 e $-40{ }^{\circ} \mathrm{C}$.
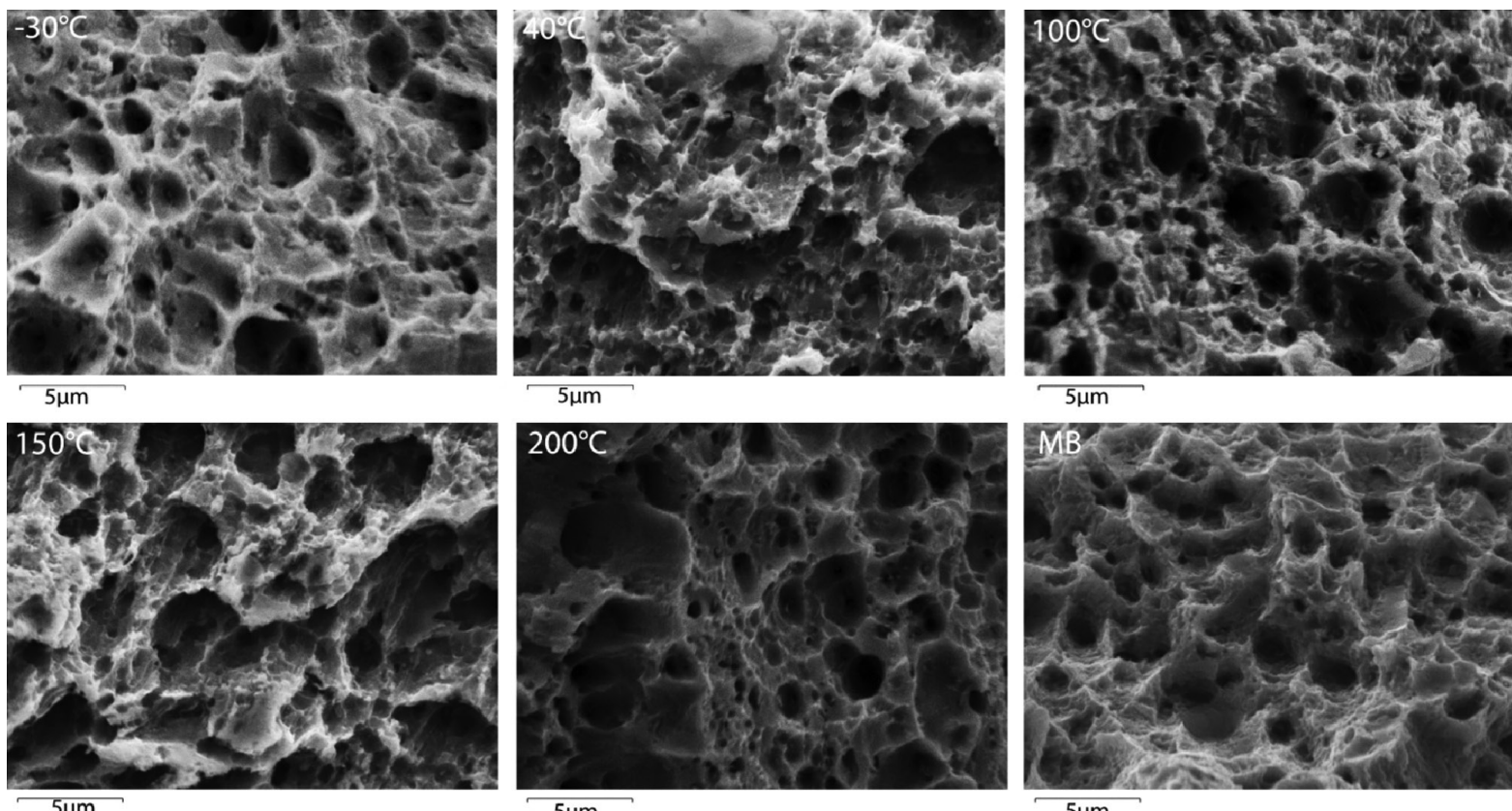

$5 \mu \mathrm{m}$

$5 \mu \mathrm{m}$

$5 \mu \mathrm{m}$

Figura 10. Imagens através do MEV das superfícies de fratura das amostras após o ensaio de tração.

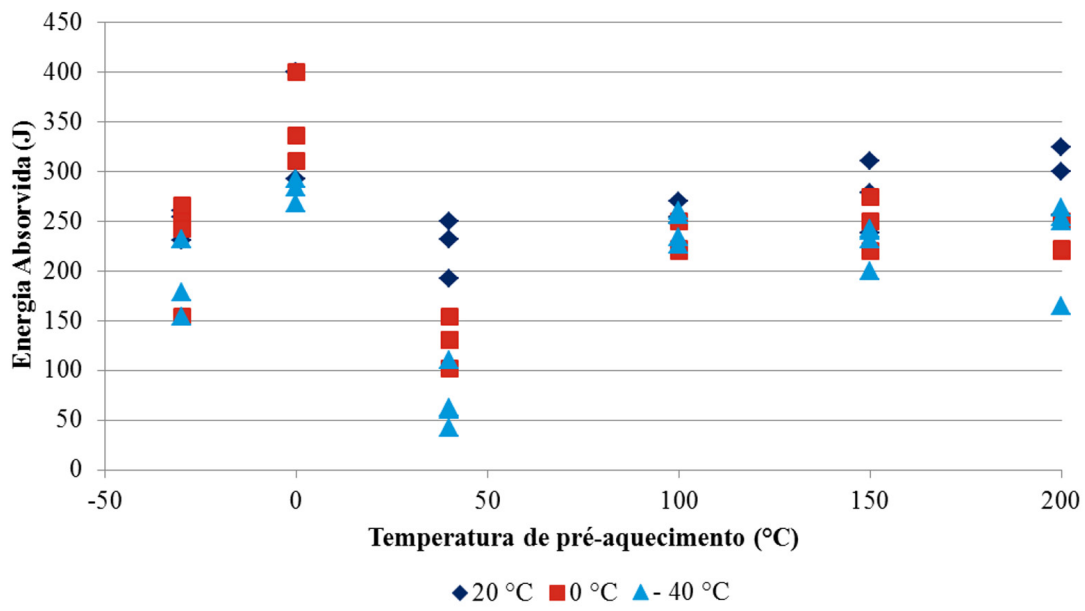

Figura 11. Energia absorvida no ensaio de impacto Charpy- $V$ do metal de solda, em função da temperatura de pré-aquecimento e da temperatura de realização do ensaio. Na temperatura de pré-aquecimento de $0{ }^{\circ} \mathrm{C}$ estão os resultados do metal base para comparação. 
A junta soldada com $40{ }^{\circ} \mathrm{C}$ de pré-aquecimento apresentou os menores valores de energia absorvida. Os resultados das juntas soldadas a $-30^{\circ} \mathrm{C}$ e a $100{ }^{\circ} \mathrm{C}$ foram similares na temperatura de ensaio de $20{ }^{\circ} \mathrm{C}$, sendo que energia absorvida aumentou com a elevação da temperatura de pré-aquecimento da junta soldada. Nas temperaturas de ensaio de $0{ }^{\circ} \mathrm{C} \mathrm{e}-40^{\circ} \mathrm{C}$ as juntas soldadas com pré-aquecimentos de $-30,100,150$ e $200{ }^{\circ} \mathrm{C}$ apresentaram resultados similares e a junta soldada a $40{ }^{\circ} \mathrm{C}$ apresentou os piores resultados.

A norma API 5L [4] requer um mínimo de $40 \mathrm{~J}$ na temperatura de teste de $0{ }^{\circ} \mathrm{C}$ para o aço de dutos. Nesta investigação, mesmo o pior resultado numa temperatura de impacto inferior apresentou valor de energia absorvida superior ao mínimo exigido por esta norma. Os valores elevados de tenacidade medidos das juntas soldadas podem ser atribuídos a recristalização devido aos passes subsequentes [16]. O metal base apresentou os maiores valores de tenacidade no ensaio de impacto Charpy- $V$, pois o metal base possui pequenas e dispersas inclusões e precipitados de MA além de um grão altamente refinado. Todas as amostras apresentaram grande número de precipitados de MA, o que reduziu a sua tenacidade.

A Figura 12 apresenta as superfícies de fratura das amostras após o ensaio de impacto Charpy- $\mathrm{V}$ realizado a $-40^{\circ} \mathrm{C}$. Nestas imagens é possível verificar uma superfície de fratura dúctil, com grande número de microcavidades. No canto superior esquerdo de cada imagem encontrasse a temperatura de pré-aquecimento e temperatura de interpasse de cada junta soldada e MB é a imagem do metal base.

\subsection{Imagens do MEV}

A baixa resistência ao impacto da solda realizada com $40^{\circ} \mathrm{C}$ de pré-aquecimento pode ser atribuída ao longo tempo que ela permaneceu em altas temperaturas, isto é, mais de duas horas de resfriamento entre cada passe. Este longo tempo em altas temperaturas, (maiores que $100^{\circ} \mathrm{C}$ ) provavelmente produziu um envelhecimento do metal, levando à alta resistência mecânica e baixa tenacidade, sendo que trabalhos [17-19] similares mencionam que é produzido neste caso elevada proporção de constituintes MA. Além disto, em um estudo [20] foi realizado tratamento térmico de reaquecimento do aço X80 em várias temperaturas após a laminação controlada com resfriamento acelerado. Este aquecimento se constituiu num tratamento de envelhecimento, aumentando a resistência mecânica e o tamanho dos precipitados de MA, mas reduzindo a razão entre a tensão de escoamento e
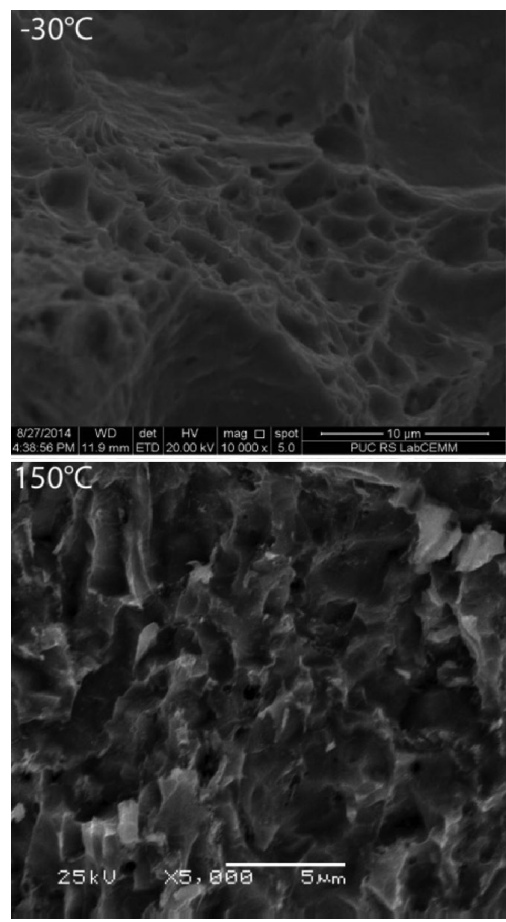
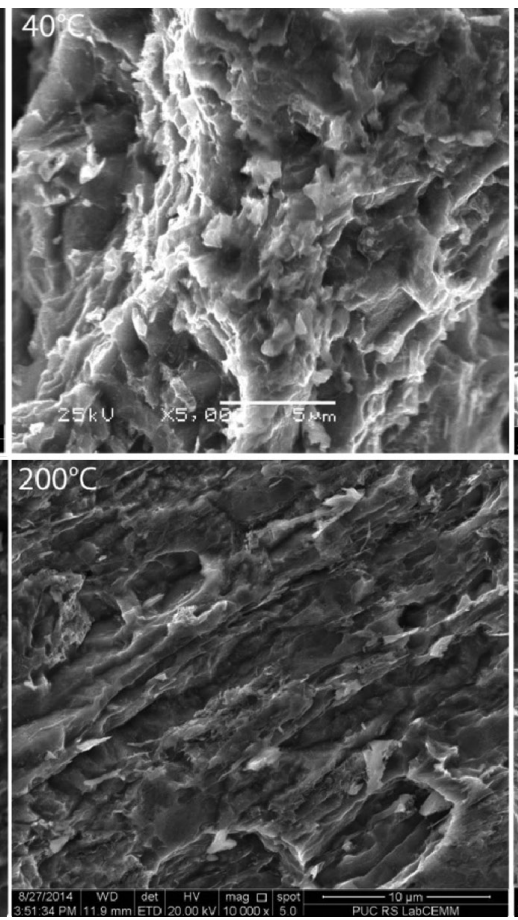
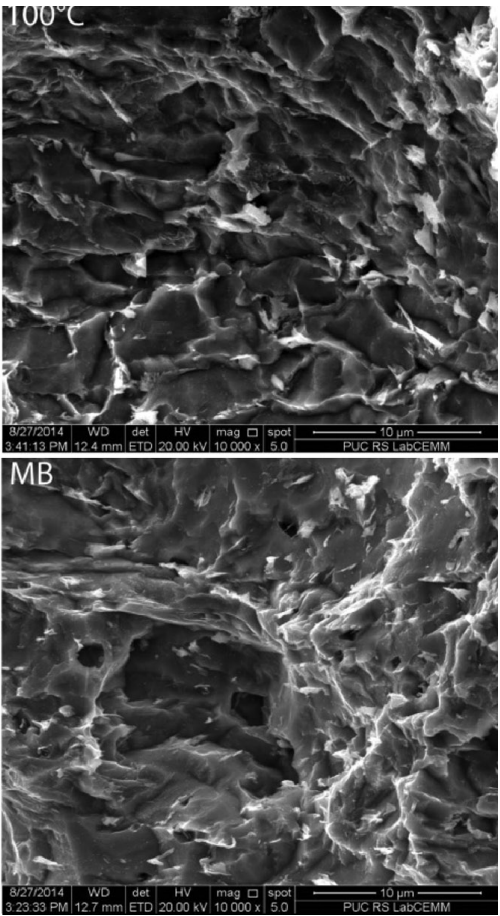

Figura 12. Imagens de MEV das superfícies de fratura das amostras após o ensaio Charpy- $\mathrm{V}$ realizado a $-40{ }^{\circ} \mathrm{C}$. 

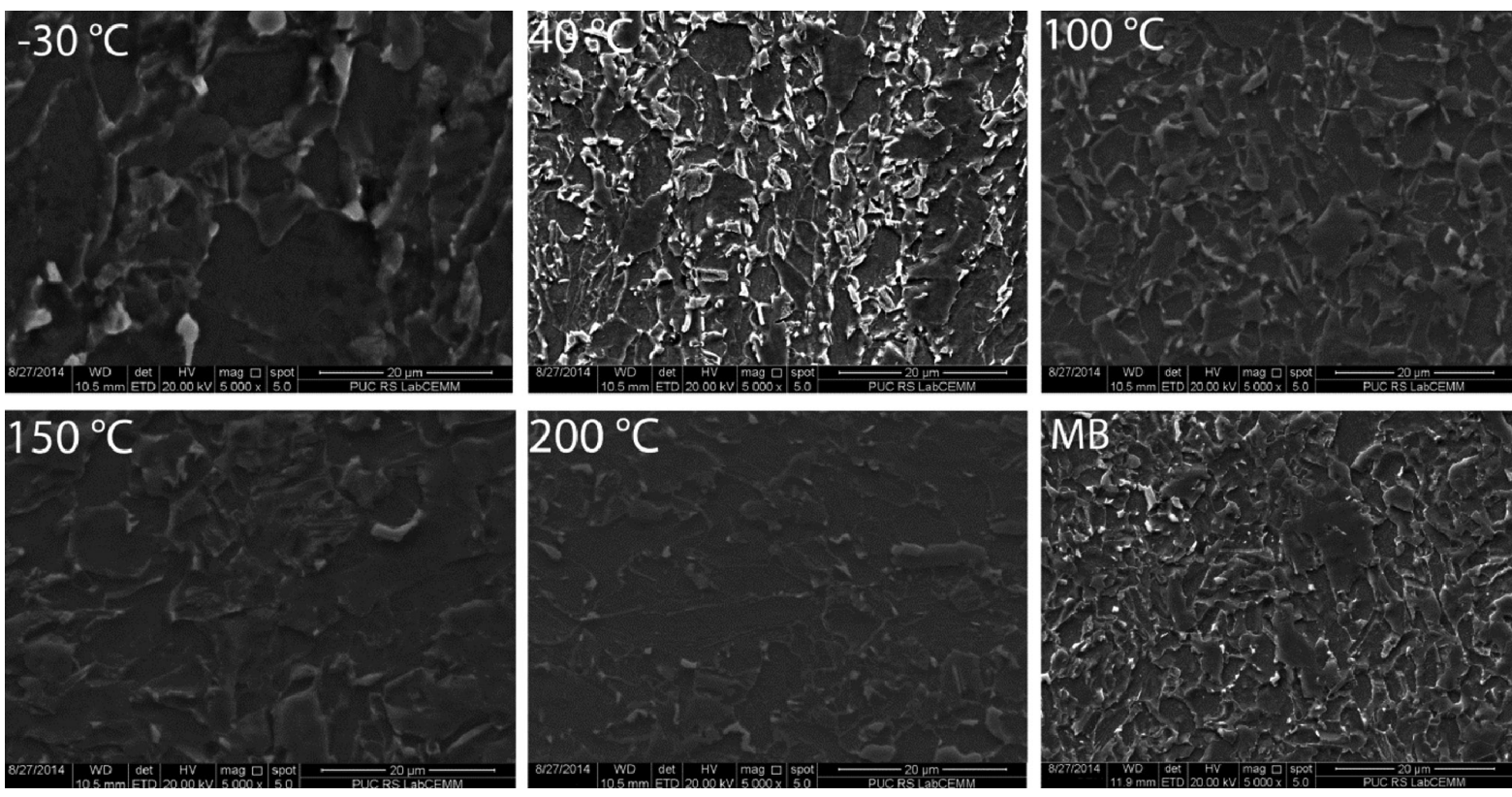

Figura 13. Imagens do MEV da terceira região da ZAC e do metal base para comparação. Os precipitados claros são do microconstituinte MA.

a tensão de ruptura e, também, reduzindo a tenacidade do aço. A Figura 13 mostra as imagens do MEV da terceira região da ZAC e do metal base, onde o microconstituinte MA aparece como um precipitado claro.

\subsection{Ensaio de dobramento}

No ensaio de dobramento das juntas soldadas não foram detectadas descontinuidades. Uma busca minuciosa por defeitos foi realizada nas interfaces do metal de solda com a ZAC e na interface da ZAC com o metal base, não tendo sido encontrado qualquer defeito.

Em suma, os resultados da junta soldada com $40^{\circ} \mathrm{C}$ de pré-aquecimento foram os piores, porém, em aplicações de construção de dutovia, é improvável que a soldagem seja realizada na condição estudada de pré-aquecimento, ou seja, após cada passe esperar aproximadamente duas horas até a junta atingir à temperatura de $40^{\circ} \mathrm{C}$ antes de fazer o próximo passe.

As propriedades mecânicas das soldas realizadas a $-30{ }^{\circ} \mathrm{C}$ e a $100{ }^{\circ} \mathrm{C}$ foram similares. As realizadas a 150 e $200^{\circ} \mathrm{C}$ apresentaram as maiores resistência ao impacto e, ainda assim, suas propriedades mecânicas foram superiores às do metal base.

\section{Conclusões}

O controle da temperatura de pré-aquecimento e de interpasse nas superfícies exteriores e interiores do duto mostrou ser este um método impreciso para o controle da temperatura de interpasse, pois a temperatura no interior da junta se tornava maior a cada passe de solda, enquanto que a temperatura nessas superfícies se mantinha constante, levando as soldas a terem, em cada passe, uma menor taxa de resfriamento.

A ZAC da soldagem realizada com pré-aquecimento e temperatura de interpasse de $40{ }^{\circ} \mathrm{C}$ provavelmente envelheceu, devido ao elevado tempo de permanência em temperaturas superior aos $100^{\circ} \mathrm{C}$. Isso pode ter degradado a sua tenacidade, e aumentou os valores de tensão de escoamento e de ruptura, os quais foram superiores aos valores medidos nas demais juntas.

O aço API 5L-X80 é um aço microligado e pode sofrer Baking em temperaturas superiores a $100^{\circ} \mathrm{C}$, desde que o tempo seja longo como foi o caso da soldagem realizada com temperatura de pré-aquecimento e de interpasse de $40^{\circ} \mathrm{C}$. 
Foi possível realizar soldagens em temperaturas negativas, com propriedades mecânicas similares às das soldagens realizadas com pré-aquecimento e temperatura de interpasse de $150^{\circ} \mathrm{C}$, conforme testes de dobramento tração e Charpy-V.

A máxima dureza foi obtida no metal de solda, com perda gradual de dureza desde a ZAC até o metal base termicamente inalterado. Não ocorreram picos de dureza na ZAC, o que provavelmente reduziria a tenacidade.

Os termopares do tipo $S$ permitiram medir a temperatura de início da transformação da austenita para ferrita no metal de solda e esta temperatura apresentou uma pequena flutuação com o aumento da taxa de resfriamento.

As diferentes taxas de resfriamento fizeram com que as máximas durezas ocorressem em diferentes locais da junta soldada. Na soldagem realizada com $40^{\circ} \mathrm{C}$ de pré-aquecimento, as máximas durezas ocorreram no centro da junta. Na soldagem realizada com $-30^{\circ} \mathrm{C}$ de pré-aquecimento, as máximas durezas ocorreram nas superfícies externa e interna da junta. Nos demais pré-aquecimentos, as máximas durezas ocorreram na metade superior do chanfro e próxima da superfície interna do duto.

\section{Referências}

[1] Hillenbrand HG, Heckmann CJ, Niederhoff KA. X80 line pipe for large-diameter high strength pipelines. Ratingen: Europipe $\mathrm{GmbH}$; 2002. (Technical Publications).

[2] Albuquerque SF, Silva RS, Maciel TM, Almeida DM, Bracarense A. Estudo do comportamento do aço API $5 \mathrm{~L}$ X80 quando submetido à soldagem por processo automatizado. Soldagem \& Inspeção. 2012;17(2):137-146. http://dx.doi.org/10.1590/ S0104-92242012000200007.

[3] American Petroleum Institute - API. API 1104: Standard for welding pipelines and related facilities. 19. ed. Washington: API; 2005.

[4] American Petroleum Institute - API. API 5L: Specification for line pipe. 44. ed. Washington: API; 2007.

[5] Wiebe J, Scheller W, Bruns C, Schmidt T. Influence of heat input during GMAW on the mechanical properties of seamless line pipe steels up to X80. In: Proceedings of the Twenty-first International Offshore and Polar Engineering Conference; 2011 Junho 19-24; Maui, Hawaii, USA. Maui: International Society of Offshore and Polar Engineers; 2011. p. 19-24.

[6] Kim C-M, Lee J-B, Yoo J-Y. A study on the metallurgical and mechanical characteristics of the weld joint of X80 Steel. In: Proceedings of The Fifteenth (2005) International Offshore and Polar Engineering Conference; 2005 Junho 19-24; Seoul, Korea. Korea: The International Society of Offshore and Polar Engineers; 2005. p. 158-162.

[7] Associação Brasileira de Normas Técnicas - ABNT. ABNT NBR 6152: Materiais metálicos - Ensaio de tração à temperatura ambiente. Rio de Janeiro: ABNT; 2002.

[8] American Standard for Testing Materals - ASTM. ASTM E190: Standard test method for guided bend test for ductility of welds. West Conshohocken: ASTM International; 2008.

[9] Zhixiong ZHU. Structure property correlation in the weld HAZ of high strength line pipe steels [tese de doutorado]. Austrália: Univesity of Wologong; 2013.

[10] Nicholas JM, Abson DJ. The prediction of maximum HAZ hardness in various regions of multiple pass welds. In: Proceedings of the 17th International Conference Computer Technology in Welding and Engineering; 2008 Junho 18-19; Cranfield, England. Cranfield: TWI; 2008. p. 27-35.
[11] Aydin, H. Relationship between a bainitic structure and the hardness in the weld zone of the friction-stir welded X80 API-grade pipe-line steel. Materiali in Tehnologije. 2014;48(1):15-22.

[12] Yang Z, Debroy T. Modeling macro-and microstructures of gas-metal-arc welded HSLA-100 steel. Metallurgical and Materials Transactions England. B. 1999;30(3):483-493. http:// dx.doi.org/10.1007/s11663-999-0082-x.

[13] Gorni AA, Mei PR. Austenite transformation and age hardening of HSLA-80 and ULCB steels. Journal of Materials Processing Technology. 2004;155-156:1513-1518. http://dx.doi.org/10.1016/j. jmatprotec.2004.04.245.

[14] Goodall GR, Gianetto J, Bowker J, Brochu M. Thermal simulation of HAZ regions in modern high strength steel. Canadian Metallurgical Quarterly. 2012;51(1):58-66. http://dx.doi.org/ 10.1179/1879139511Y.0000000023.

[15] Kang KB, Kang JS, Yoo JY, Seo DH, Suh IS, An GB. Development of high strength and high performance linepipe and shipbuilding steels. In: Weng Y, Dong H, Gan Y, editors. Advanced Steels. Berlin: Springer; 2011. p. 281-288.. http://dx.doi.org/10.1007/978-3642-17665-4_29.

[16] Cruz-Crespo A, Bezerra De Araujo D, Scotti A. Effect of tempering pass on HSLA-80 steel HAZ microstructures. Welding Journal. 2013;92(10):304s-311s.

[17] Zhang X, Gao H. A study of impact toughness of intercritically reheated coarse-grain heat effected zone of two type X80 grade pipeline steel. Transactions of JWRI. 2012;2011:101-104.

[18] Zhou M, Du L, Liu X. Microstructure and mechanical properties of X80 pipeline steels in different cooling schedules. Acta Metallurgica Sinica. English Letters. 2010;23(3):171-175.

[19] Niu J, Qi L-H, Liu Y-L, Ma L, Feng Y-R, Zhang J-X. Tempering microstructure and mechanical properties of pipeline steel X80. Transactions of Nonferrous Metals Society of China. 2009;19(Suppl 3):s573-s578. http://dx.doi.org/10.1016/S10036326(10)60111-2.

[20] Ishikawa N, Okatsu M, Endo S, Shikanai N, Muraoka R, Kondo J. Mechanical and metallurgical properties of grade $X 80$ high strain linepipe produced by heat treatment on-line process. In: The Eighteenth International Offshore and Polar Engineering Conference; 2008 Julho 6-11; Vancouver, Canada. Vancouver: The International Society of Offshore and Polar Engineers; 2008. p. $13-20$. 